\title{
Hubungan antara Prestasi Belajar pada Anak dengan Gangguan Tidur di SDN 03 Pondok Cina Depok
}

\author{
Nuri Indahwati, Rini Sekartini \\ Departemen Ilmu Kesehatan Anak Fakultas Kedokteran Universitas Indonesia
}

\begin{abstract}
Latar belakang. Prevalensi gangguan tidur pada anak terbanyak terjadi pada anak usia sekolah. Di Indonesia, prevalensi gangguan tidur pada anak tergolong cukup tinggi, tetapi kesadaran orang tua masih rendah. Gangguan tidur pada anak dapat berdampak pada prestasi belajar anak.

Tujuan. Mengetahui hubungan antara gangguan tidur dan faktor sosiodemografi dengan prestasi belajar anak usia sekolah.

Metode. Studi potong lintang dilakukan pada Oktober 2015-September 2016 terhadap anak berusia 7-12 tahun di SDN 03 Pondok Cina, Depok. Orang tua anak mengisi kuesioner sosiodemografi dan kuesioner sleep disturbance scale for children. Prestasi belajar didapat dari nilai rapor mata pelajaran Bahasa Indonesia, Matematika, dan Ilmu Pengetahuan Alam (IPA).

Hasil. Sejumlah 154 subjek melengkapi kuesioner dan didapatkan prevalensi gangguan tidur 44,8\%, dengan jenis terbanyak gangguan transisi tidur-bangun (50,6\%). Gangguan tidur berhubungan dengan prestasi belajar yang rendah pada pelajaran Matematika ( $\mathrm{p}=0,006)$ dan nilai rata-rata Bahasa Indonesia, Matematika, dan IPA ( $\mathrm{p}=0,025)$. Faktor sosiodemografi yaitu usia anak, jenis kelamin, usia ibu, pendidikan terakhir ibu, pekerjaan ibu, pendapatan ayah, pendapatan ibu, dan bentuk keluarga berpengaruh terhadap prestasi belajar anak.
\end{abstract}

Kesimpulan. Gangguan tidur dan beberapa faktor sosiodemografi berhubungan dengan prestasi belajar anak usia sekolah. Sari Pediatri 2016;18(3):175-81

Kata kunci: gangguan tidur, prestasi belajar, anak usia sekolah, siswa sekolah dasar

\section{Academic performance of Children with Sleep Disorders in SDN Preliminary School 03 Pondok Cina Depok}

\begin{abstract}
Nuri Indahwati, Rini Sekartini
Background. Sleep disorders in children are the most prevalent in school-aged children. The prevalence of sleep disorders in Indonesia is relatively high, but most of parents are not aware of this. Sleep disorders may influence academic performance of children. Objective. To find the effects of sleep disorders and sociodemography factors to academic performance of school-aged children. Method. This cross-sectional study was performed in October 2015-September 2016 to 7-12 years old children in SDN 03 Pondok Cina, Depok. Subjects filled questionnaire of sociodemography and Sleep Disturbance Scale for Children questionnaire. Academic performance are scores of Indonesian Language, Mathematics, and Sciences obtained from student report book.

Result. 154 subjects filled the questioner completely. The prevalence of sleep disorder was $44.8 \%$, with the most problem was sleepwake transition disorders (50.6\%). Sleep disorders influenced academic performance of Mathematics $(\mathrm{p}=0.006)$ and the average of three subjects: Indonesian Languages, Mathematics, and Sciences ( $\mathrm{p}=0.025)$. Child's age and gender; maternal's age, education, occupation, and income; pathernal's income; and family structure are sociodemography factors that affected the academic performance. Conclusion. In conclusion, sleep disorders and sociodemography factors influenced the academic performance of school-aged children. Sari Pediatri 2016;18(3):175-81
\end{abstract}

Keywords: sleep disorders, academic performance, school-aged children, elementary school students

Alamat korespondensi: DR. Dr. Rini Sekartini, SpA(K). Departemen IKA Fakultas Kedokteran Universitas Indonesia/RS Dr. Cipto Mangunkusumo, Jakarta. E-mail: rsekartini@yahoo.com,nuri.indahwati@yahoo.com 


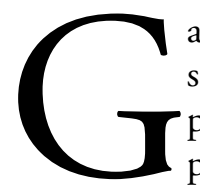

angguan tidur merupakan masalah yang sering ditemukan pada anak. Sebuah penelitian terhadap anak usia $0-18$ tahun di pelayanan kesehatan primer menunjukkan prevalensi gangguan tidur 3,7\% dan terbanyak terjadi pada usia sekolah $(4,7 \%) .{ }^{1}$ Beberapa penelitian epidemiologi juga menunjukkan prevalensi gangguan tidur yang tinggi, di antaranya 25\% di Amerika Serikat dan 21,2\% pada anak usia 2-12 tahun di Cina. ${ }^{2}$ Demikian pula prevalensi gangguan tidur pada anak juga tinggi terjadi di Indonesia. Remaja usia 12-15 tahun $(62,9 \%)$ mengalami gangguan tidur, jenis terbanyak berupa gangguan transisi tidur-bangun tidur $(63,6 \%){ }^{3}$ Sementara itu, studi epidemiologi lain mengenai snoring menunjukkan 29,3\% siswa sekolah dasar di Jakarta Barat mengalami snoring. ${ }^{4}$ Terlepas dari tingginya prevalensi tersebut, $42,3 \%$ orang tua menganggap bahwa gangguan tidur pada anak bukan merupakan masalah. ${ }^{5}$

Gangguan tidur berdampak terhadap berbagai aspek kehidupan anak, di antaranya pembelajaran (learning), memori (memory), perhatian (attention), regulasi emosi (emotional regulation), dan keberhasilan akademis (academic success). Suatu penelitian menyebutkan bahwa anak usia sekolah dasar dengan tidur yang tidak memadai cenderung bermasalah di sekolah atau memiliki kesehatan yang buruk. ${ }^{6}$ Gangguan tidur yang berkaitan dengan durasi tidur berdampak pada kemampuan kognitif yang buruk, masalah perilaku, dan fungsi akademis yang terganggu. ${ }^{7}$ Berdasarkan suatu studi epidemiologi, gangguan tidur persisten hingga usia 5 tahun pada kelompok dengan risiko tinggi berkaitan dengan kegelisahan/depresi dan agresi serta nilai IQyang lebih rendah dibandingkan dengan kelompok dengan faktor risiko rendah. ${ }^{8}$

Meskipun demikian, perhatian orang tua terhadap gangguan tidur anak di Indonesia masih kurang. ${ }^{5}$ Prevalensi gangguan tidur yang tinggi pada anak usia sekolah dan kesadaran orang tua yang rendah, jumlah penelitian mengenai gangguan tidur serta dampaknya pada anak usia sekolah di Indonesia sangat kurang. Penelitian ini bertujuan untuk mengetahui prevalensi gangguan tidur serta pengaruh gangguan tidur dan faktor-faktor lain terhadap prestasi belajar pada siswa di sekolah dasar.

\section{Metode}

Studi potong lintang (cross sectional) yang dilakukan selama bulan Januari 2016 di SDN 03 Pondok Cina, Depok. Subjek penelitian adalah siswa SDN 03 Pondok Cina Depok. Kriteria inklusi adalah siswa duduk di kelas 2,3,4, dan 5; memiliki rapor yang telah berisi nilai untuk mata pelajaran Matematika, Ilmu Pengetahuan Alam (IPA), dan Bahasa Indonesia minimal selama dua semester; dan orang tua subjek menandatangani informed consent dan bersedia mengisi kuesioner. Subjek didapatkan melalui teknik total sampling. Subjek mengisi kuesioner faktor sosiodemografi, kuesioner sleep disorder scale for children (SDSC) untuk diagnosis gangguan tidur, serta lembar informed consent.

Faktor sosiodemografi yang diteliti, meliputi usia, jenis kelamin, urutan kelahiran, jumlah saudara kandung, usia orang tua, pendidikan terakhir orang tua, pekerjaan orang tua, status ekonomi (pendapatan) dan bentuk keluarga. Diagnosis gangguan tidur berdasarkan kuesioner SDSC. Subjek mengalami gangguan tidur jika total nilai kuesioner lebih besar dari 45. Prestasi belajar didapatkan melalui nilai rapor untuk mata pelajaran yang diujikan pada ujian akhir sekolah berstandar nasional (UAS BN) yang terdiri atas Matematika, IPA, dan Bahasa Indonesia pada semester terakhir. Rata-rata dari ketiga mata pelajaran kemudian dibandingkan dengan nilai rata-rata kelas untuk masing-masing mata pelajaran tersebut.

Pengolahan dan analisis data dilakukan dengan software SPSS for Windows 20.0. Analisis bivariat menggunakan analisis hipotesis komparatif kategorik tidak berpasangan dengan uji chi-square. Nilai $p<0,05$ menunjukkan hubungan yang bermakna secara statistik. Penelitian ini telah mendapat izin lolos etik dari Komite Etik Fakultas Kedokteran Universitas Indonesia.

\section{Hasil}

Didapatkan 219 siswa kelas 2, 3, 4, dan 5 dari SDN 03 Pondok Cina yang menerima kuesioner. Seratus sembilanpuluh siswa mengembalikan kuesioner dan telah mengisi lembar informed consent, 39 drop out karena tidak mengembalikan kuesioner, dan 36 dieksklusi sehingga didapatkan subjek yang dianalisis 154 (70,32\%) subjek.

Sebagian besar subjek berjenis kelamin laki-laki, berusia 7-9 tahun, memiliki orang tua berpendidikan menengah, ayah berpendapatan di atas rata-rata, 
Nuri Indahwati dkk: Hubungan antara prestasi belajar pada anak dengan gangguan tidur

Tabel 1 Sebaran karakteristik subjek

\begin{tabular}{|c|c|c|}
\hline Variabel & Jumlah (n) & Persentase (\%) \\
\hline \multicolumn{3}{|l|}{ Usia (tahun) } \\
\hline $7-9$ & 97 & 63,0 \\
\hline $10-12$ & 57 & 37,0 \\
\hline \multicolumn{3}{|l|}{ Kelas } \\
\hline 2 & 34 & 22,1 \\
\hline 3 & 32 & 20,8 \\
\hline 4 & 46 & 29,9 \\
\hline 5 & 42 & 27,2 \\
\hline \multicolumn{3}{|l|}{ Jenis kelamin } \\
\hline Laki-laki & 87 & 56,5 \\
\hline Perempuan & 67 & 43,5 \\
\hline \multicolumn{3}{|l|}{ Urutan kelahiran } \\
\hline Pertama & 64 & 41,6 \\
\hline Tengah & 23 & 14,9 \\
\hline Terakhir & 67 & 43,5 \\
\hline \multicolumn{3}{|l|}{ Jumlah saudara } \\
\hline$>1$ & 63 & 40,9 \\
\hline$\leq 1$ & 91 & 59,1 \\
\hline \multicolumn{3}{|l|}{ Usia ayah (tahun) } \\
\hline$>45$ & 38 & 24,7 \\
\hline$\leq 45$ & 111 & 72,1 \\
\hline Almarhum & 5 & 3,2 \\
\hline \multicolumn{3}{|l|}{ Usia ibu (tahun) } \\
\hline$>45$ & 16 & 10,4 \\
\hline$\leq 45$ & 137 & 89,0 \\
\hline Almarhumah & 1 & 0,6 \\
\hline \multicolumn{3}{|l|}{ Pendidikan terakhir ayah } \\
\hline Rendah & 31 & 20,1 \\
\hline Menengah & 89 & 57,8 \\
\hline Tinggi & 34 & 22,1 \\
\hline \multicolumn{3}{|l|}{ Pendidikan terakhir ibu } \\
\hline Rendah & 38 & 24,7 \\
\hline Menengah & 91 & 59,1 \\
\hline Tinggi & 25 & 16,2 \\
\hline \multicolumn{3}{|l|}{ Pekerjaan ayah } \\
\hline Bekerja & 123 & 79,9 \\
\hline Tidak bekerja & 31 & 20,1 \\
\hline \multicolumn{3}{|l|}{ Pekerjaan ibu } \\
\hline Bekerja & 30 & 19,5 \\
\hline Tidak bekerja & 124 & 80,5 \\
\hline \multicolumn{3}{|l|}{ Pendapatan ayah } \\
\hline Di atas garis kemiskinan & 120 & 77,9 \\
\hline Di bawah garis kemiskinan & 34 & 22,1 \\
\hline \multicolumn{3}{|l|}{ Pendapatan ibu } \\
\hline Di atas garis kemiskinan & 39 & 25,3 \\
\hline Di bawah garis kemiskinan & 115 & 74,7 \\
\hline \multicolumn{3}{|l|}{ Bentuk keluarga } \\
\hline Keluarga inti & 139 & 90,3 \\
\hline Extended family & 15 & 9,7 \\
\hline
\end{tabular}

Catatan: variabel pekerjaan ayah dan pekerjaan ibu dibagi menjadi kategori bekerja dan tidak bekerja untuk keperluan analisis faktor sosiodemografi
Tabel 2. Sebaran subjek berdasarkan gangguan tidur $(\mathrm{n}=69)$

\begin{tabular}{lcc}
\hline Variabel & $\begin{array}{c}\text { Jumlah } \\
(\mathrm{n})\end{array}$ & $\begin{array}{c}\text { Persentase } \\
(\%)\end{array}$ \\
\hline Gangguan tidur & 69 & 44,8 \\
Gangguan memulai dan & 46 & 29,9 \\
mempertahankan tidur & & \\
Gangguan pernapasan saat tidur & 14 & 9,1 \\
Gangguan kesadaran & 29 & 18,8 \\
Gangguan transisi tidur-bangun & 78 & 50,6 \\
Gangguan somnolen berlebihan & 38 & 24,7 \\
Hiperhidrosis saat tidur & 43 & 27,9 \\
\hline Keterang 1 subjek dapat memiliki lebih dari 1 jenis
\end{tabular}

dan tinggal dengan keluarga inti. Sebaran faktor sosiodemografi tertera pada Tabel 1. Didapatkan prevalensi gangguan tidur $44,8 \%$, terbanyak berupa gangguan memulai dan mempertahankan tidur. Prevalensi gangguan tidur terterta pada Tabel 2. Sebaran prestasi belajar didapatkan subjek sebagian besar memiliki prestasi belajar tinggi untuk mata pelajaran IPA dan rata-rata ketiga mata pelajaran (Bahasa Indonesia, Matematika, dan IPA). Sebaran prestasi belajar subjek tidak ditampilkan pada tabel.

Berdasarkan hasil uji chi square didapatkan hubungan yang bermakna antara usia ibu dan pekerjaan ibu dengan prestasi belajar Bahasa Indonesia; terdapat hubungan yang bermakna antara usia ibu, pendidikan terakhir ibu, dan bentuk keluarga dengan prestasi belajar Matematika; terdapat hubungan yang bermakna antara usia anak, jenis kelamin, usia ibu, pekerjaan ibu, pendapatan ayah, dan pendapatan ibu dengan prestasi belajar IPA; serta diperoleh hubungan yang bermakna antara pekerjaan ibu, pendapatan ayah dan pendapatan ibu dengan nilai rata-rata ketiga mata pelajaran yaitu Bahasa Indonesia, Matematika, dan IPA. Analisis bivariat dengan uji chi square juga menunjukkan hubungan yang bermakna antara gangguan tidur dan gangguan kesadaran dengan prestasi belajar mata pelajaran Matematika; serta hubungan yang bermakna antara gangguan tidur dengan prestasi belajar nilai rata-rata namun tidak terdapat hubungan yang bermakna antara jenis-jenis gangguan tidur dengan prestasi belajar berdasarkan nilai rata-rata. Hasil analisis hubungan antara gangguan tidur dan faktor sosiodemografi dengan prestasi belajar pada siswa SDN 03 Pondok Cina Depok tertera pada Tabel 4. 
Nuri Indahwati dkk: Hubungan antara prestasi belajar pada anak dengan gangguan tidur

Tabel 4. Hubungan antara faktor sosiodemografi dengan prestasi belajar

\begin{tabular}{|c|c|c|c|c|c|c|c|c|c|c|c|c|}
\hline \multirow[t]{3}{*}{ Variabel } & \multicolumn{12}{|c|}{ Prestasi belajar } \\
\hline & \multicolumn{2}{|c|}{ Bahasa Indonesia } & \multirow[t]{2}{*}{$\mathrm{p}$} & \multicolumn{2}{|c|}{ Matematika } & \multirow[t]{2}{*}{$\mathrm{p}$} & \multicolumn{2}{|c|}{ IPA } & \multirow[t]{2}{*}{$\mathrm{p}$} & \multicolumn{2}{|c|}{ Nilai rata-rata } & \multirow[t]{2}{*}{$\mathrm{p}$} \\
\hline & Rendah & Tinggi & & Rendah & Tinggi & & Rendah & Tinggi & & Rendah & Tinggi & \\
\hline \multicolumn{13}{|l|}{ Usia (tahun), $(\mathrm{n}=154)$} \\
\hline $7-9$ & 48 & 49 & \multirow[t]{2}{*}{1,000} & 50 & 47 & \multirow[t]{2}{*}{0,902} & 37 & 60 & \multirow[t]{2}{*}{0,027} & 42 & 55 & \multirow[t]{2}{*}{0,113} \\
\hline $10-12$ & 29 & 28 & & 28 & 29 & & 33 & 24 & & 33 & 24 & \\
\hline \multicolumn{13}{|l|}{ Jenis kelamin $(n=154)$} \\
\hline Laki-laki & 37 & 50 & \multirow[t]{2}{*}{0,051} & 42 & 45 & \multirow[t]{2}{*}{0,611} & 31 & 56 & 0,009 & 36 & 51 & 0,056 \\
\hline Perempuan & 40 & 27 & & 36 & 31 & & 39 & 28 & & 39 & 28 & \\
\hline Urutan kelahiran $(\mathrm{n}=154)$ & & & & & & & & & & & & \\
\hline Pertama & 34 & 30 & 0,807 & 33 & 31 & 0,954 & 31 & 33 & 0,724 & 33 & 31 & 0,829 \\
\hline Tengah & 11 & 12 & & 11 & 12 & & 11 & 12 & & 11 & 12 & \\
\hline Terakhir & 32 & 35 & & 34 & 33 & & 28 & 39 & & 31 & 36 & \\
\hline Jumlah saudara $(\mathrm{n}=154)$ & & & & & & & & & & & & \\
\hline$>1$ & 31 & 32 & 1,000 & 35 & 28 & 0,396 & 29 & 34 & 1,000 & 31 & 32 & 1,000 \\
\hline$\leq 1$ & 46 & 45 & & 43 & 48 & & 41 & 50 & & 44 & 47 & \\
\hline Usia ayah, tahun $(\mathrm{n}=149)$ & & & & & & & & & & & & \\
\hline$>45$ & 17 & 21 & 0,541 & 19 & 19 & 1,000 & 14 & 24 & 0,283 & 15 & 23 & 0,241 \\
\hline$\leq 45$ & 58 & 53 & & 55 & 56 & & 54 & 57 & & 58 & 53 & \\
\hline Usia ibu, tahun $(\mathrm{n}=153)$ & & & & & & & & & & & & \\
\hline$>45$ & 52 & 24 & 0,001 & 59 & 17 & 0,001 & 62 & 14 & 0,001 & 10 & 66 & 0,412 \\
\hline$\leq 45$ & 25 & 52 & & 10 & 67 & & 12 & 65 & & 6 & 71 & \\
\hline $\begin{array}{l}\text { Pendidikan terakhir ayah } \\
(\mathrm{n}=154)\end{array}$ & & & & & & & & & & & & \\
\hline Rendah & 17 & 14 & 0,484 & 19 & 12 & 0,092 & 15 & 16 & 0,403 & 17 & 14 & 0,533 \\
\hline Menengah & 46 & 43 & & 47 & 42 & & 43 & 46 & & 44 & 45 & \\
\hline Tinggi & 14 & 20 & & 12 & 22 & & 12 & 22 & & 14 & 20 & \\
\hline $\begin{array}{l}\text { Pendidikan terakhir ibu } \\
(\mathrm{n}=154)\end{array}$ & & & & & & & & & & & & \\
\hline Rendah & 19 & 19 & 0,529 & 26 & 12 & 0,003 & 19 & 19 & 0,323 & 21 & 17 & 0,168 \\
\hline Menengah & 48 & 43 & & 46 & 45 & & 43 & 48 & & 46 & 45 & \\
\hline Tinggi & 10 & 15 & & 6 & 19 & & 8 & 17 & & 8 & 17 & \\
\hline Pekerjaan ayah $(\mathrm{n}=154)$ & & & & & & & & & & & & \\
\hline Bekerja & 63 & 60 & 0,688 & 60 & 63 & 0,470 & 55 & 68 & 0,869 & 60 & 63 & 1,000 \\
\hline Tidak bekerja & 14 & 17 & & 18 & 13 & & 15 & 16 & & 15 & 16 & \\
\hline Pekerjaan ibu $(\mathrm{n}=154)$ & & & & & & & & & & & & \\
\hline Bekerja & 9 & 21 & 0,025 & 13 & 17 & 0,490 & 7 & 23 & 0,012 & 9 & 21 & 0,038 \\
\hline Tidak bekerja & 68 & 56 & & 65 & 59 & & 63 & 61 & & 66 & 58 & \\
\hline Pendapatan ayah $(\mathrm{n}=154)$ & & & & & & & & & & & & \\
\hline Di atas garis kemiskinan & 55 & 65 & 0,080 & 56 & 64 & 0,096 & 47 & 73 & 0,006 & 52 & 68 & 0,021 \\
\hline Di bawah garis & 22 & 12 & & 22 & 12 & & 23 & 11 & & 23 & 11 & \\
\hline kemiskinan & & & & & & & & & & & & \\
\hline Pendapatan ibu (n=154) & & & & & & & & & & & & \\
\hline Di atas garis kemiskinan & 14 & 25 & 0,064 & 14 & 25 & 0,052 & 9 & 30 & 0,002 & 11 & 28 & 0,005 \\
\hline Di bawah garis & 63 & 52 & & 64 & 51 & & 61 & 54 & & 64 & 51 & \\
\hline kemiskinan & & & & & & & & & & & & \\
\hline Bentuk keluarga $(\mathrm{n}=154)$ & & & & & & & & & & & & \\
\hline Keluarga inti & 70 & 69 & 1,000 & 65 & 74 & 0,008 & 62 & 77 & 0,710 & 65 & 74 & 0,233 \\
\hline Extended family & 7 & 8 & & 13 & 2 & & 8 & 7 & & 10 & 5 & \\
\hline Gangguan tidur & & & & & & & & & & & & \\
\hline Tidak gangguan tidur & 39 & 46 & 0,331 & 34 & 51 & 0,006 & 34 & 51 & 0,178 & 34 & 51 & 0,025 \\
\hline Gangguan tidur & 38 & 31 & & 44 & 25 & & 36 & 33 & & 41 & 28 & \\
\hline
\end{tabular}

Catatan: untuk keperluan analisis hubungan antara faktor sosiodemografi dengan prestasi belajar anak, usia ayah dan ibu dibagi menjadi kategori $\leq 45$ tahun dan $>45$ tahun. Ayah dan ibu yang almarhum/almarhumah tidak diikutkan dalam analisis data. Nilai p pada tabel merupakan hasil analisis bivariat. 


\section{Pembahasan}

Prevalensi gangguan tidur siswa sekolah dasar umur 7-12 tahun (44,8\%) lebih besar dibandingkan dengan siswa sekolah menengah pertama di Jakarta $(39,7 \%) .{ }^{9}$ Keduanya menggunakan metode SDSC untuk diagnosis gangguan tidur, tetapi dengan rentang usia yang berbeda (12-15 tahun). Hasil pada penelitian kami juga lebih tinggi dibandingkan dengan penelitian diagnosis gangguan tidur berdasarkan ICD-9 yang dilakukan di layanan kesehatan primer (4,7\%) pada anak usia sekolah (6-12 tahun). ${ }^{1}$ Jenis gangguan tidur terbanyak berupa gangguan transisi tidur-bangun sesuai dengan hasil penelitian Adelina $\mathrm{dkk}^{3}$ dan Christine $\mathrm{dkk},{ }^{10}$ tetapi pada usia anak yang berbeda (12-15 tahun). Hasil penelitian kami berbeda dengan penelitian Fijri dkk $^{9}$ terhadap anak berusia 12-15 tahun yang menyatakan gangguan memulai dan mempertahankan tidur sebagai prevalensi jenis gangguan tidur terbanyak.

Beberapa faktor sosiodemografi memengaruhi prestasi belajar anak. Hasil penelitian kami sesuai dengan Fijri $\mathrm{dkk}^{9}$ yang melaporkan mengenai hubungan faktor sosioekonomi terhadap prestasi belajar, semakin tinggi status sosioekonomi dapat meningkatkan kesempatan anak untuk memiliki pendidikan yang baik. Terdapat hubungan antara pendapatan ayah terhadap prestasi belajar IPA dan prestasi berdasarkan nilai rata-rata serta terdapat pengaruh antara pendapatan ibu dengan prestasi belajar IPA dan nilai rata-rata. Demikian pula yang dikemukakan oleh Sharif $\mathrm{dkk}^{11}$ bahwa semakin tinggi pendapatan keluarga, semakin baik pula prestasi belajar anak.Untuk variabel pendidikan orang tua, penelitian kami sesuai dengan penelitian Bjorklund dan Salvanes ${ }^{12}$ yang melaporkan terdapat hubungan antara tingkat pendidikan orang tua dengan anak. Latar belakang orang tua dapat memengaruhi anaknya baik dari segi kognitif, pendidikan, kesehatan, dan lain-lain. Berbeda dengan hasil penelitian Fijri $\mathrm{dkk}^{9}$ yang melaporkan tidak terdapat hubungan antara tingkat pendidikan orang tua dengan prestasi belajar pada anak.

Terdapat hubungan antara pendidikan ibu terhadap prestasi belajar matematika. Hal tersebut sejalan dengan penelitian Carneiro $\mathrm{dkk}^{17}$ yang menunjukkan pengaruh pendidikan ibu pada hasil mata pelajaran matematika dan membaca pada anak berusia 7-8 tahun. Ibu dengan pendidikan yang lebih tinggi dapat menyediakan suasana keluarga yang lebih baik untuk anaknya dengan menunda kehamilan, meningkatkan pendapatan keluarga, dan assortative mating. ${ }^{13}$

Tidak terdapat hubungan antara pendidikan terakhir ayah dengan prestasi belajar. Hasil tersebut berbeda dengan Carneiro dan Heckman ${ }^{15}$ yang melaporkan adanya hubungan antara pendidikan ayah dengan prestasi belajar anak. Berdasarkan penelitian tersebut, pendidikan ayah memengaruhi pendapatan permanen keluarga sehingga memengaruhi pilihan pendidikan pada anaknya. Penelitian lain oleh Chevalier $\mathrm{dkk}^{13}$ melaporkan bahwa pendidikan ayah lebih berpengaruh pada anak perempuan namun dengan mekanisme yang belum diketahui.

Terdapat hubungan antara pekerjaan ibu dengan prestasi belajar bahasa Indonesia, IPA, dan rata-rata pelajaran bahasa Indonesia, matematika, dan IPA. Yetis-Bayrakar $\mathrm{dkk}^{16}$ melaporkan bahwa kompleksitas pekerjaan ibu berpengaruh secara positif terhadap nilai matematika dan nilai membaca anak dengan hubungan yang lebih besar pada anak laki-laki. Menurut Carneiro $\mathrm{dkk}^{17}$ ibu dengan pendidikan yang baik juga memiliki pekerjaan di luar rumah yang berpengaruh negatif terhadap pendidikan anak.

Prestasi belajar IPA berpengaruh pada usia anak, jenis kelamin anak, dan bentuk keluarga. Muhibbin $\mathrm{dkk}^{18}$ melaporkan bahwa usia anak memengaruhi prestasi belajarnya. Sementara Fijri $\mathrm{dkk}^{9}$ melaporkan bahwa prestasi belajar yang rendah berhubungan dengan jenis kelamin laki-laki. Fijri dkk juga melaporkan hubungan antara anak yang tinggal dengan keluarga inti dengan prestasi belajar yang baik. Hal tersebut diperkuat penelitian oleh Uwaifo ${ }^{19}$ yang melaporkan bahwa anak yang tinggal dengan keluarga inti memiliki emosional yang lebih stabil dan memiliki masalah emosional yang lebih sedikit.

Usia ibu memengaruhi prestasi belajar bahasa Indonesia, matematika dan IPA. Orang tua usia muda belum siap secara emosional dan finansial yang mengakibatkan perawatan dan pendidikan anak tidak optimal. ${ }^{20}$ Sebaliknya, penundaan kelahiran anak pertama dapat memberikan kesempatan bagi ibu untuk melanjutkan pendidikan ke jenjang yang lebih tinggi. ${ }^{21}$ Di sisi lain, kami tidak memperoleh hubungan antara usia ayah dengan prestasi belajar. Sementara itu, Shields $\mathrm{dkk}^{22}$ melaporkan bahwa usia ayah berpengaruh secara positif terhadap prestasi belajar anak saat SMA dan pendidikan awal pada perguruan tinggi.

Kami tidak mendapatkan hubungan antara urutan 
Nuri Indahwati dkk: Hubungan antara prestasi belajar pada anak dengan gangguan tidur

kelahiran dan jumlah saudara terhadap prestasi belajar anak. Berbeda dengan hasil penelitian Shields $\mathrm{dkk}^{22}$ yang melaporkan hubungan negatif antara urutan kelahiran dengan prestasi belajar anak saat SMA. Penelitian Shields juga melaporkan bahwa jumlah saudara tidak menunjukkan hubungan dengan prestasi belajar anak, semakin sedikit saudara yang dimiliki, semakin baik prestasi belajar.Terdapat hubungan antara gangguan tidur dengan prestasi belajar Matematika dan rata-rata ketiga mata pelajaran. Sebagian besar anak dengan gangguan tidur memiliki prestasi belajar Matematika maupun rata-rata ketiga mata pelajaran yang rendah dibandingkan dengan anak yang tidak mengalami gangguan tidur. Hal tersebut sesuai dengan Fijri $\mathrm{dkk}^{9}$ yang melaporkan bahwa terdapat hubungan antara gangguan tidur dengan pencapaian prestasi akademis yang rendah (average IQ), meskipun studi tersebut dilakukan terhadap rentang usia anak yang berbeda, yaitu 12-15 tahun.

Penelitian kami berbeda dengan penelitian Hendri $\mathrm{dkk}^{4}$ yang melaporkan bahwa terdapat hubungan antara snoring (salah satu gejala sleep-disordered breathing) terhadap nilai rerata yang lebih rendah untuk pelajaran bahasa Indonesia, matematika, dan IPA, serta ratarata ketiga mata pelajaran tersebut pada anak snoring dibandingkan dengan tidak snoring. Namun, kami mendapatkan bahwa tidak terdapat hubungan antara gangguan tidur dengan prestasi belajar Bahasa Indonesia dan prestasi belajar IPA. Untuk jenis gangguan tidur, diperoleh hubungan antara gangguan kesadaran dengan prestasi belajar Matematika. Sebagian besar anak dengan prestasi belajar tinggi tidak mengalami gangguan kesadaran. Namun, belum terdapat penelitian, khususnya di Indonesia, mengenai hubungan antara jenis gangguan tidur berdasarkan kuesioner SDSC terhadap prestasi belajar anak.

Beberapa penelitian mengenai gangguan tidur di Indonesia belum pernah meneliti mengenai gangguan tidur berdasarkan diagnosis kuesioner SDSC pada anak usia sekolah, khususnya di Depok. Keterbatasan penelitian kami di antaranya tidak melibatkan seluruh siswa di SDN 03 Pondok Cina; terdapat beberapa kuesioner yang tidak terisi lengkap atau tidak dikembalikan oleh subjek karena kuesioner yang diisi orang tua diberikan melalui anak dan tidak diberikan secara langsung kepada orang tua; sampel yang belum dapat mewakili keadaan anak usia sekolah secara umum sebab hanya diambil dari satu sekolah saja; serta terdapat beberapa faktor yang tidak diteliti pada penelitian yang mungkin dapat memengaruhi prestasi belajar anak.

\section{Kesimpulan}

Prevalensi gangguan tidur di SDN 03 Pondok Cina, Depok sebesar 44,8\%. Terdapat beberapa faktor sosiodemografi yang berpengaruh terhadap prestasi belajar anak, yaitu usia anak, jenis kelamin anak, usia ibu, pendidikan terakhir ibu, pekerjaan ibu, pendapatan ayah, pendapatan ibu, dan bentuk keluarga. Terdapat hubungan antara gangguan tidur dengan prestasi belajar matematika.

\section{Daftar pustaka}

1. Meltzer L, Johnson C, Crosette J, Ramos M, Mindell J. Prevalence of Diagnosed Sleep Disorders in Pediatric Primary Care Practices. Pediatrics 2010;125:1410-8.

2. Liu X. Brief Report: An Epidemiologic Survey of the Prevalence of Sleep Disorders Among Children 2 to 12 Years Old in Beijing, China. Pediatrics 2005;115:266-8.

3. Adelina H, Almitra R, Alia A, Anandika P, Achmad U, Amalia S, dkk. Prevalensi gangguan tidur pada remaja usia 12-15 tahun di sekolah lanjutan tingkat pertama. Sari Pediatri 2009;11:149-54.

4. Hendri TJ, Darmawan BS, Hanifah O. Hubungan habitual snoring dengan prestasi akademis anak sekolah dasar. Sari Pediatri 2014;15:313-8.

5. Rini $S$, Adi NP. Gangguan tidur pada anak usia bawah tiga tahun di lima kota di Indonesia. Sari Pediatri 2006;7:188-93.

6. Smaldone A, Honig JC, Byrne MW. Sleepless in America: inadequate sleep and relationships to health and well-being of our nation's children. Pediatrics 2007 119:s29-s37.

7. Gruber R. Short sleep duration is associated with teacherreported inattention and cognitive problems in healthy schoolaged children. Nat Sci Sleep 2012;4:33-40.

8. Sheridan A, Murray L, Cooper P, Evangeli M, Byram V, Halligan S. A longitudinal study of child sleep in high and low risk families: Relationship to early maternal settling strategies and child psychological functioning. J Clin Sleep Med 2013;14:266-73.

9. Fijri A, Rini S, Irawan M. Academic achievement of junior high school students with sleep disorders. Paediatrica Indones 2015;55:50-8.

10. Chistine N, Rini S, Hardiono P. Skala gangguan tidur untuk anak (SDSC) sebagai instrument skrining gangguan tidur 
pada anak sekolah lanjutan tingkat pertama. Sari Pediatri 2011;12:365-72.

11. Sharif I, Wills TA, Sargent JD. Effect of visual media use on school performance: a prospective study. J Adolesc Health 2010;46:52-61.

12. Björklund A, Salvanes KG. Chapter 3 - Education and family background: mechanisms and policies. Dalam: Eric A, Hanushek SM, Ludger W, penyunting Handbook of the economics of education. Philadelphia: Elsevier Saunders; 2011.h.201-47.

13. Chevalier A, Harmon C, O' Sullivan V, Walker I. The impact of parental income and education on the schooling of their children. J Labor Econom 2013;2:8.

14. McLachlan R, Gilfillan G, Gordon J. Deep and persistent disadvantage in Australia. Australian Government Productivity Commission Staff Working Paper. Canberra: Australian Government Productivity Commission; 2013.

15. Carneiro P, Heckman JJ. Human capital policy. Dalam: Heckman JJ, Krueger AB, penyunting. Inequality in America. Cambridge: MIT Press; 2004.
16. Yetis-Bayraktar A, Budig M, Tomaskovic-Devey D. From the Shop Floor to the Kitchen Floor: Maternal Occupational Complexity and Children's Reading and Math Skills. Work and Occupations 2012;40:37-64.

17. Carneiro P, Meghir C, Parey M. Maternal education, home environments, and the development of children and adolescents. J Eu Economic Assoc 2012;11:123-60.

18. Muhibbin S, penyunting. Psikologi pendidikan: dengan pendekatan baru. Bandung: Remaja Rosdakarya; 2008.

19. Uwaifo VO. The effects of family structure and parenthood on the academic performance in Nigerian University students. Stud Home Comm Sci 2008;2:121-4.

20. Leigh AGong X. Does Maternal Age Affect Children's Test Scores?. Aus Econ Rev 2010;43:12-27.

21. Duncan GJ, Lee KTH, Rosakes-Rueda M, Kalil A, Ziol-Guest K. Maternal age and child achievement. Irvine: University of California; 2016 (revise and resubmit).

22. Shields N, Hanneke C. The Effects of Parental Age and Sibling Configurations on Family Environment and Academic Achievement of Children. J Appl Soc Sci 2008;2: 13-25. 